\title{
The prevalence of autoimmune thyroiditis after universal salt iodisation in Sri Lanka
}

\section{R F Fernando ${ }^{1}$, P C Chandrasinghe ${ }^{1}$, A A Pathmeswaran ${ }^{2}$}

(Index words: goiter, thyroiditis, iodised salt, Sri Lanka)

\begin{abstract}
Introduction Sri Lanka is endemic for goiters. lodine deficiency is thought to be the main cause. The global iodisation programme was implemented in the country in 1995. Several studies done in school children have shown a reduction in the goiter prevalence $(3.8 \%)$ in the initial post iodisation period. An island wide, community
\end{abstract}

based study was carried out to study the prevalence of goiters.

Methods A multistage cluster sampling method was used. Examination of goiters was done by two trained investigators and graded according to the WHO grading. Fine needle aspiration cytology of the goitres was also undertaken in the field. A sample of urine was collected

${ }^{1}$ University Surgical Unit, North Colombo Teaching Hospital, Ragama and ${ }^{2}$ Department of Public Health, University of Kelaniya, Sri Lanka.

Correspondence: RFF, e-mail: <ranilfern@s/tnet.lk>. Received 28 October 2011 and revised version accepted 13 January 2012. Competing interests: none declared. 
from all participants. In a random sample of 153 individuals with a goiter, serum was checked for anti thyroid peroxidase antibodies.

Results Out of 5200 individuals screened, 426 had a clinically detectable goiter. Adjusted prevalence rate was $6.8 \%$. Both serological and cytological evidence of autoimmune thyroiditis was seen in $19.6 \%$ of goiters. Mean urinary iodine concentration was $235 \mu \mathrm{g} / \mathrm{l}$ range $11.1-425 \mu \mathrm{g} / \mathrm{l})$. Association between elevated antithyroperoxidase antibodies and median urinary iodine concentration was significant.

Conclusion Goiter prevalence in Sri Lanka has increased after an initial drop following the iodisation. A significant proportion of goiters is due to AIT. Urinary excretion of lodine in the community is high and has a positive correlation with the prevalence of aTPO anti vodies. Increase in AIT due to a high lodine intake may account for the rise in goiter prevalence.

\section{Ceylon Medical Journal 2012; 57: 116-119}

\section{Introduction}

Sri Lanka is endemic for goiter. Iodine deficiency is considered to be the main aetiology for this endemicity [1]. Iodisation of salt in Sri Lanka began in 1995 and to date over $92 \%$ of households consume iodised salt [2]. Universal Salt Iodisation Programme initiated by the WHO is aimed at preventing iodine deficiency disorders [3]. Iodisation programmes have been of undoubted benefit. However, high intake of iodine detected by high urinary iodine content had been shown to increase the prevalence of autoimmune thyroiditis (AIT) and papillary cancer [4]. There is no data on prevalence AIT in Sri Lanka. In the early post iodisation period, the median urinary iodine levels were above the cut-off point of $100 \mu \mathrm{g} / 1$ in all provinces except in the Uva Province [5]. The highest median urinary iodine level was reported in North Central Province $(231.3 \mu \mathrm{g} / \mathrm{l})$. Overall, $35.4 \%$ of the children had urine iodine levels in the 'ideal' range (100-199.9 $\mu \mathrm{g} / 1) ; 30.6 \%$ with lower values $(<100 \mu \mathrm{g} / \mathrm{l})$ indicated iodine deficiency and $16.3 \%$ with higher values $(>300 \mu \mathrm{g} / \mathrm{l})$ indicated excessive iodine intake. Only $49.5 \%$ of households had used adequately iodised salt at that time. national survey in 2005 should a median urinary iodine concentration above $100 \mu \mathrm{g} / \mathrm{l}$ in all provinces of the country [6]. Over $90 \%$ of households had access to adequately iodised salt. It was observed in the same study that $61 \%$ of salt samples had iodine values higher than the recommended range (recommended range 15-25 ppm) by the year 2005 [3]. Studies by have shown rising titres of anti thyroglobulin antibodies (aTGA) in Sri Lankan school girls after the iodisation programme [7]. The age related prevalence of high titres of aTGA ranged between $11 \%$ to $69 \%$. Same study reported that there was no evidence of thyroid induced thyrotoxicosis after examining 363 schoolgirls of 11-16 years from Colombo, Kandy, Matale, Kalutara and
Galle districts. With the backdrop of above findings we carried out a subgroup analysis of a national survey to assess the epidemiology of autoimmune thyroiditis.

\section{Methods}

As part of a national study on epidemiology and prevalence of goiters, data are collected on prevalence of thyroiditis, urinary iodine and iodine content of drinking water. This was a descriptive cross-sectional study involving all areas of the country excluding the North and the Batticalo district in the East. The study period was from August 2007 to June 2008. Approval for the study was granted by the Ethical Review Committee of the Faculty of Medicine, University of Kelaniya. The country was divided into six areas based on rain fall patterns and geography namely; wet zone - costal (WZC - Z1), wet zone - hills (WZH - Z2), dry zone - east (DZE - Z3), dry zone - north central (DZNC - Z4), intermediate zone - north (IZN - Z5), intermediate zone - south (IZS - Z6) (Figure 01). The required minimum sample size for each zone was 864 . This was calculated using a $10 \%$ estimated prevalence of goiter based on literature with an acceptable error of $2 \%$ on either side of the point estimate (total width of the $95 \%$ confidence interval - 4\%). Based on logistical considerations it was decided to recruit a sample of 50 eligible individuals from 18 villages in each zone. The 18 villages were selected using the probability proportionate to size (PPS) technique. All individuals above 10 years of age were included in the study. The examination of study participants for goiter was done by at least two investigators and confirmed by the principal investigator. The goiters were graded according to the WHO grading [8]. Fine needle aspiration cytology (FNAC) of the goiters was also undertaken in the field by a medical professional after obtaining informed written consent. A sample of urine and water from the drinking source were collected. Based on FNAC findings goiters were grouped in to those with definitive features of AIT, borderline features of AIT and no features of AIT. From each of these three groups a random sample of individuals was selected for serum analysis for anti-thyroperoxidase antibodies (aTPO). The sample size for serological evaluation was decided based on the expectation that $30 \%$ participants with benign histology and $60 \%$ of participants with autoimmune histology to have elevated antibody levels. To detect this difference with an alpha of 0.05 and power of $80 \%$, fifty were needed in each group. Enzyme-linked immunosorbant assay (ELISA) was used for in vitro assay of aTPO antibodies in human sera. Data analysis was done with SPPS version 18 statistical package.

\section{Results}

A total of 5200 individuals were screened and 426 were clinically detected as having goiters. Out of the total population $66 \%$ were females ( median age - 38 years; range 10 -92). The overall calculated adjusted prevalence 
of goiter was $6.8 \%$. Out of the 426 goiters, 112 had cytological evidence of AIT. The sample selected for antibody testing totalled 153 . Among these 54 had definite and another 54 had borderline cytological features of thyroiditis. This sample contained $88.8 \%$ females. Sixty four out of $153(41.8 \%)$ had raised antibody levels. Only 30 individuals $(19.6 \%)$ had both cytological and serological evidence of thyroiditis. Only 31 out of $153(20.36 \%)$ had both clinical and serological evidence of thyroiditis. Clinical diagnosis correlated with cytological evidence in 25 individuals (16.3\%). There was poor agreement in all the three comparisons on applying the weighted Kappa Statistic (Table 1). Superiority of one method over the other cannot be discerned. Median urinary iodine concentration of the study population was $235 \mu \mathrm{g} / \mathrm{L}$ (range: 11.1 - $425 \mu \mathrm{g} / \mathrm{l})$. Dryzone - north central reported the highest median urinary iodine concentration of $332.8 \mu \mathrm{g} / \mathrm{l}$ (range: $30-425 \mu \mathrm{g} / 1$ ) (Table 2). All zones had a median urinary concentration of above $100 \mu \mathrm{g} / \mathrm{l}$. At an ecological level percentage of subjects with elevated serum aTPO antibody levels had a positive, non-significant correlation with median urinary iodine concentration (Spearman's rho $=$ 0.44 ; $p=0.3$ (Figure 2). When zone 3 (DZE), probably an outlier, was left out the correlation became stronger and significant (Spearman's rho $=0.9 ; \mathrm{p}=0.03$ ). The median water iodine concentration in drinking water for the population was $84 \mu \mathrm{g} / \mathrm{l}$ (range: 18.2 - $427.3 \mu \mathrm{g} / \mathrm{l}$ ). There was no significant difference between the values in the different zones (Figure 3).

Table 1. Agreement between different methods of diagnosing AIT

\begin{tabular}{lccc}
\hline \multicolumn{4}{c}{ Agreement Expected } \\
& & $\begin{array}{c}\text { Weighted } \\
\text { Kappa }\end{array}$ \\
\hline Histology and serology & 60.13 & 51.03, & 0.15 \\
Histology and clinical diagnosis & 48.37 & 50.97 & -0.05 \\
Serology and clinical diagnosis & 56.86 & 51.03 & 0.11 \\
\hline
\end{tabular}

Table 2. Median values of urinary and drinking water lodine concentration for the six zones.

\begin{tabular}{lcc}
\hline Zone & $\begin{array}{c}\text { Median urinary } \\
\text { iodine concentration } \\
(\text { range }) \mu g / l\end{array}$ & $\begin{array}{c}\text { Median water } \\
\text { iodine level } \\
\text { (range) } \mu g / l\end{array}$ \\
\hline Z1-WZC & $227.2(12.1-398.7)$ & $79.8(22.7-378)$ \\
Z2-WZH & $161.3(18.7-411.9)$ & $83.4(29.2-427.3)$ \\
Z3-DZE & $216.9(44.3-423)$ & $79.4(20.8-274.3)$ \\
Z4-DZNC & $332.8(30-425)$ & $72.2(18.2-347.8)$ \\
Z5-IZN & $218.6(11.1-387)$ & $88.4(19.4-297.3)$ \\
Z6-IZS & $193.9(22.2-423.3)$ & $94.6(25.4-371.5)$ \\
Total population & $235.8(11.1-425)$ & $84(18.2-427.3)$ \\
\hline
\end{tabular}

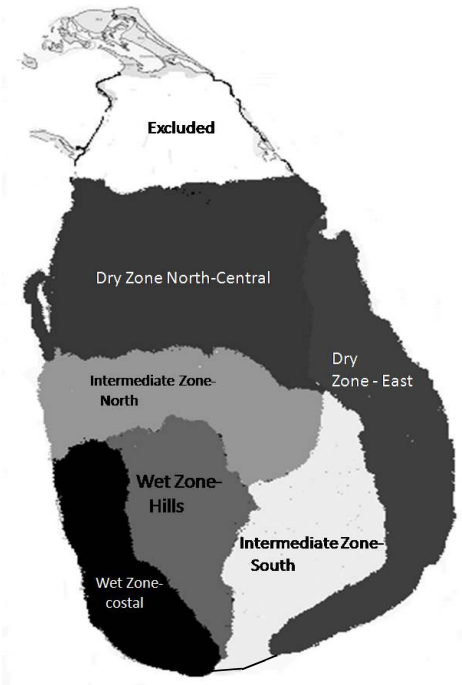

Figure 1. Division of the country in to six zones based on geography and rainfall.

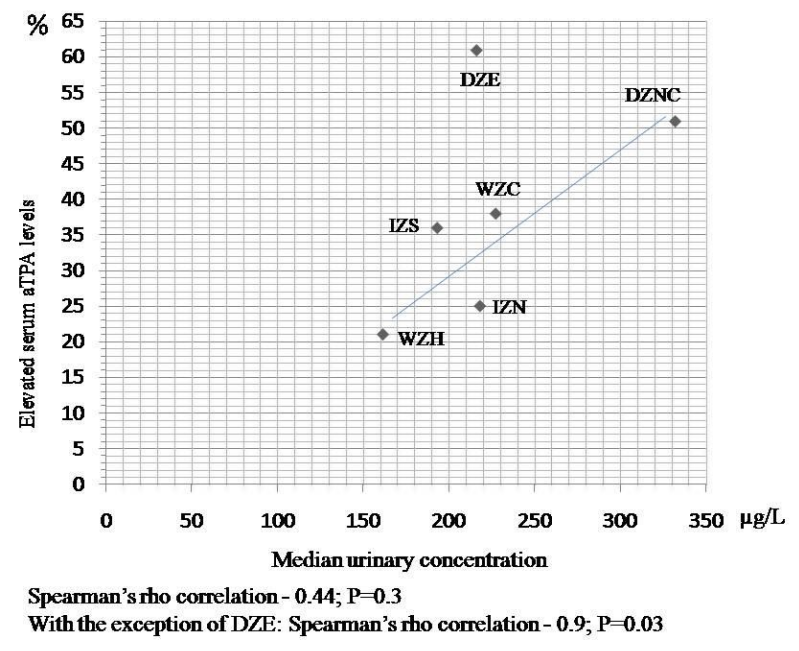

Figure 2. Association between median urinary iodine concentration and prevalence of elevated levels of anti thyroid peroxidase antibodies.

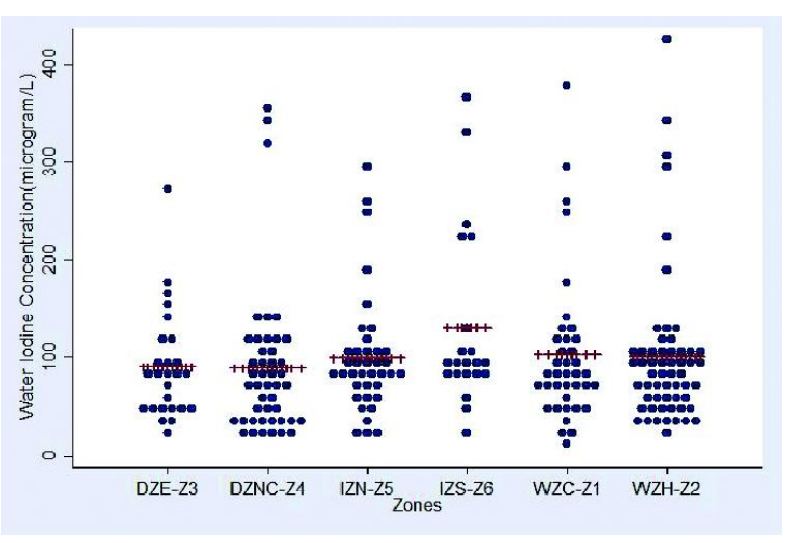

Figure 3. Concentration of iodine in drinking water in the six zones. 


\section{Discussion}

Autoimmune thyroiditis is characterised by lymphocytic infiltration of the thyroid stroma. The antibodies are directed towards thyroglobulin or thyroperoxidase enzyme. Mechanism of iodine causing thyroiditis is still obscure. Some propose that thyroid injury occurs through the generation of reactive oxygen species when both these elements are present [9]. Evidence from the United States and China showing an increase in AIT with high iodine intake suggests a similar phenomenon in humans [4-10]. Some authors have suggested that AIT is caused by high iodine intake coupled with goitrogens and not by iodine alone [11-12]. Universal iodisation programme is aimed at eradicating iodine deficiency disorders and has shown satisfactory outcome in many regions [3-5]. Yet if the deleterious effects are not taken note of, the benefits of the programme will be negated. Endemicity of goiter in Sri Lanka as alluded above was thought to be due to iodine deficiency. The goiter prevalence in Sri Lanka has decreased from $18.2 \%$ in 1986 to $3.8 \%$ in 2005 . These studies however included school children. One community based study done in the pre iodisation era reported a prevalence rate of $7 \%$ [13]. This study involved a small rural community with only 6 public health midwife divisions. Current study reported a $6.8 \%$ overall prevalence of goiter which is an increase of $3 \%$ although it should be noted that the former study was conducted amongst school children. Further the median urinary iodine concentration in the population was reported to be $145 \mu \mathrm{g} / \mathrm{l}$ in the early post-iodisation period (2000/ 2001 ) and $154 \mu \mathrm{g} / \mathrm{l}$ after 10 years of iodisation (2006). The results of the current study show a median value of $235 \mu \mathrm{g} /$ 1 (range: 11.1 - $425 \mu \mathrm{g} / \mathrm{l}$ ) which is an increase compared to the two previous values. Consistently in all studies done on urinary iodine excretion, North Central region has shown the highest urinary iodine concentration. Interestingly this region is believed to have a lesser number of households consuming iodised salt [6]. The iodine concentration in drinking water from this region is comparable to the rest of the country(Figure 3 ). This region may be having a different source of iodine. The raised level of urinary iodine excretion however confirms the adequacy of iodine consumption in the community following salt iodisation. The strong association between the prevalence of AIT and urinary iodine concentration in the current study may be showing a similar phenomenon seen in some regions of China where increased incidence of thyroiditis was detected with high iodine intake. A rising aTG antibody levels in school children in the post iodisation era supports this further [7]. It is reported that $61 \%$ of salt samples to be having a higher than recommended concentration of iodine (over $25 \mathrm{ppm}$ ) [6]. This study also revealed that none of the salt producers had written instructions on the process of iodization and the quantities to be added. In current clinical practice there is no consensus regarding the method of diagnosis of AIT. In the current study, authors have considered two out of three (clinical, cytological and serological) criteria to be present for the diagnosis of AIT. The important clinical signs considered were diffuse enlargement, firm consistency and micro-nodularity. Prevalence of AIT varies between 16 to $20 \%$ according to our data depending on the availability of diagnostic modalities. As there is no superiority in either method and considering the low cost, FNAC coupled with clinical suspicion seems to be an appropriate first line investigation.

In conclusion the overall adjusted prevalence of goiter in Sri Lanka currently is 6.8\%. This appears to be an increase in the prevalence of goiter when compared with available data. Since over $92 \%$ of households consume iodised salt and the mean urinary iodine excretion in all regions of the country has increased well above the expected level it could be postulated that this increase in goiter may be a result of some other factor than iodine deficiency. There is a significant association between urinary iodine levels and AIT. Hence it can be postulated that the rise in goiter prevalence at least partially may be due to AIT secondary to excess iodine consumption.

\section{References}

1. Fernando MA, Balasuriya S, Herath KB, Katugampola S. Endemic iodization in Sri Lanka. Asia-Pacific Journal of Public Health 1989; 3: 11-9.

2. United Nations Children's Fund, State of the World's Children (http://www.unicef.org/infobycountry/sri_lanka_ statistics.html\#87)

3. Assessment of Iodine Deficiency Disorders and Monitoring their Elimination - A Guide for Programme Managers: International Council for Control of Iodine Deficiency Disorders United NationsWHO/NHD/01.1

4. Teng W. Effect of iodine intake on thyroid diseases in China. New England Journal of Medicine 2006; 354: 2783-93.

5. Jayatissa R, Gunathilaka MM, Fernando DN. Iodine nutrition status among schoolchildren after salt iodization. Ceylon Medical Journal 2005; 48: 125-8.

6. Jayatissa R, Gunathilaka MM. Iodine Nutrition Status in Sri Lanka 2005. Department of Nutrition Medical Research Institute Department of Healthcare and Nutrition 2006.

7. Premawardhana LDKE, Parker PPA, Wijeyaratne CN, Jayasingha A, De Silva DGH, Lazarm JH. Increased prevalence of thyroglobulin antibodies in Sri Lankan schoolgirls - is iodine the cause? European Journal of Endocrinology 2000; 143: 185-8.

8. Dunn JT, Pretell EA, Daza CH, Viteri F. Toward the Eradication of Endemic Goitre, Cretinism and Iodine Deficiency. PAHO/WHO, Science Publication No. 502, Washington DC, 1986.

9. Bagchi N, Brown TR, Sundick RS. Thyroid cell injury is an initial event in the induction of autoimmune thyroiditis by iodine in obese strain chickens. Endocrinology 1995; 136: 5054-60.

10. Weaver DK, Batsakis JG, and Nishiyama RH. Relationship of iodine to lymphocytic goiters. Archives of Surgery 1968; 98: $183-6$.

11. Follis RH. Further observations on thyroiditis and colloid accumulation in hyperplastic thyroid glands of hamsters receiving excess iodine. Laboratory Investigation 1964; 13: 1590-9.

12. Belshaw BE and Becker DV. Necrosis of follicular cells and discharge of thyroidal iodine induced by administering iodide to iodine-deficient dogs. Journal of Clinical Endocrinology and Metabolism 1973; 13: 466-74.

13. Katugampola SL, Balasuriya S, Fernando MA. Prevalence of goiter in a rural community in Sri Lanka. Asia Pacific Journal of Public Health 1992-1993; 6: 182-7. 